\title{
New IGCP Projects Accepted and Starting in 2014
}

Project No.: 630. Permian-Triassic Climatic and Environmental Extremes and Biotic Response

Countries involved: Argentina, Australia, Austria, Canada, China, Croatia, Czeck Republic, France, Germany, Hungary, India, Iran, Israel, Italy, Japan, New Zealand, Norway, Poland, Romania, Russia, Slovenia, Spain, Thailand, Turkey, Switzerland, UK, USA.

Project Leaders: Zhong-Qiang Chen (China), Thomas J. Algeo (USA), Margaret L. Fraiser (USA), Steve Kershaw (UK), Jinnan Tong (China), Sylvie Crasquin (France), Michael J. Benton (UK), Guang R. Shi (Australia), Charles Henderson (Canada), Arne Winguth (USA), Paul B. Wignall (UK), Kunio Kaiho (Japan), Ghulam Bhat (India), Yuri D. Zakharov (Russia)

Duration: 2014-2018

Contact details: Prof. Zhong-Qiang Chen

State Key Laboratory of Biogeology \&

Environmental Geology

China University of Geosciences

Wuhan 430074

China

Tel: +86-27-67883068

E-mail: zhong.qiang.chen@cug.edu.cn / zqchen.uwa@gmail.com

Website: in process

Many marine ecosystems are under threat at the present day. The geological record provides numerous analogues of environmental upheavals and major biocrises, the most disruptive of which occurred during the Permian-Triassic (P-Tr) transition at $\sim 252$ million years ago. Many of the factors that contributed to the P-Tr biotic crisis, e.g., increased atmospheric carbon dioxide concentrations, rapid global warming, oceanic anoxia, and hypercapnia (CO2 poisoning) are also observed in the present day or are anticipated to develop in the near future. The Permian-Triassic transition may thus record a natural experiment in globalscale ecosystem collapse that, if properly deciphered, could provide important insights into possible responses of modern marine ecosystems to present day climate and environmental change. This project will address themes related to current global concerns and issues including the response of the biosphere to global warming, sustenance of global biodiversity, and maintaining the habitability of planet Earth.

The proposal aims to investigate the climatic and environmental extremes and ecosystem's response during the P-Tr mass extinction and its aftermath through analyses of the rock and fossil records of South China, Tibet, Japan, India, elsewhere in Asia, eastern Europe, Russia, Canada, Greenland, Spitsbergen, western US, western Australia, and New Zealand. Through detailed studies of latest Permian to Early Triassic biostratigraphy, palaeontology, palaeoecology, sedimentology, geochemistry, and biogeochemistry in the above regions, this project will attempt to document global ecosystem's collapse and rebuilding in seas and on land, formulate the mechanism biotic response to climatic and environmental extremes at fossil group and ecosystem levels; to reconstruct the global latest Permian to Early Triassic oceanic and climatic conditions and probe mutual effect mechanism between extreme environment and high temperature; and to correlate all of this data in a global stratigraphic framework. Ultimately, this project will: (1) reveal climatic and environmental extremes at a global scale and their impacts on ecosystems in seas and on land, (2) elucidate the factors controlling biotic recovery in various habitats and climate zones, (3) determine the similarities and differences in the responses of different marine groups to biotic crisis, and (4) assess the effects of climate or other geological events on the restoration of the defaunated marine ecosystems.

These goals will be achieved primarily by collaborative fieldwork in key latest Permian to Early Triassic successions in $>10$ different countries over five years and related laboratory work in over 20 different countries. The results of our project, which are to be published in four and special volumes or edited books, in international peer-reviewed journals, in annual symposium proceedings and on the World Wide Web, will advance scientific understanding of the interactions between the biosphere and geosphere and lead to a better understanding of ancient defaunation events. The firm support and active involvement in this project of most top scientists in this field from around the world will lead to unique training opportunities for postgraduate students from a range of countries (Argentina, Austria, Australia, Canada, China, India, Japan, France, Germany, Iran, Russia, Switzerland, Thailand, UK, USA) as well as professionals from developing and developed regions alike. As a result, the proposed project will provide a friendly platform for participants to communicate their own research results and also bring together global experts, and research facilities to solve a truly global-scale problem. The competitive track records of the proposers underscore this project's high chance of academic success as well as its potential to achieve significant societal benefits in the form of knowledge sharing and enhanced scientific cooperation between nations.

\section{Project No.: 632. Continental Crises of the} Jurassic

Countries involved: China, Morocco, USA, Sweden, Greenland and New Zealand

Project Leaders: Jingeng Sha (China), Vivi Vajda (Sweden), Paul E. Olsen (USA), Emma Sammel Msaky (Tanzania), Mohammed EtTouhami (Morocco), Olena Shevchuk (Ukraine), Hamish Campbell (New Zealand), Wolfram M. Kürschner (Norway)

Duration: 2014-2018

Contact details: Prof. Dr. Jingeng Sha

Nanjing Institute of Geology and

Palaeontology

Academia Sinica, Chi-Ming-Ssu

39 East Beijing Road

Nanjing 210008

China

Tel: + 862583282181

E-mail: jgsha@nigpas.ac.cn

Website: in process

This IGCP project will more specifically focus on the Jurassic Period, starting with the mass extinction event that occurred 202 million years ago just prior to the TriassicJurassic boundary, through the Toarican anoxic event 183 million year ago and finally covering the Jurassic-Cretaceous boundary at 145 million years ago where major lake systems expanded over continents. The Jurassic and Cretaceous constitute the 'age of the dinosaurs', a time interval with green 
house conditions when perennially warm vegetation types extended into the highlatitudes of Scandinavia, Greenland, China and in fact to the poles. The research focuses on major events and their relation to climatic and environmental changes within these ancient lacustrine ecosystems, and the correlation with the marine realm.

Additionally, our project has a strong component of applied Earth sciences because these sediments host significant fossil fuel resources, including coal, gas and petroleum that are stored in the sub-surface.

Organic-rich shales and limestones are a prominent feature of most of our target areas.
Particularly high total organic carbon content values are found in the paleo-tropics and high latitudes areas such as Eastern North America, Greenland, Scandinavia, Australia, and China. They have long been recognized as source rocks for coal, natural gas and oil, and have more recently been recognized as significant, unconventional resources that can be accessed through technological innovations, including horizontal drilling. Although future development of prosperous societies rely on access to energy resources, the negative effects of burning fossil fuels needs to be mitigated. One method successfully employed and developed, partly by the Swedish Geological Survey is $\mathrm{CO}_{2}$ sequestration where carbon dioxide is removed from flue gases at point sources such as power stations, before being stored in underground reservoirs. Another $\mathrm{CO}_{2}$ sequestration system that lends itself to a specific aspect of the geology of the Jurassic, the extremely widespread presence of flood basalts in both Northern and Southern hemispheres, is mafic rock carbonation in which $\mathrm{CO}_{2}$ reacts with rock in the reservoir to produce limestone. The feasibility to implement these methods will be investigated through sedimentological and geochemical studies in the outlined study areas. 